13,14

\title{
Ячеистый беспорядок наноглобул желатина
}

\author{
(ㄱ Д.В. Новиков \\ Санкт-Петербургский государственный лесотехнический университет им. С.М. Кирова, \\ Санкт-Петербург, Россия \\ E-mail: dvnovikov65@mail.ru
}

Поступила в Редакцию 8 апреля 2021 г.

В окончательной редакции 12 апреля 2021 г.

Принята к публикации 12 апреля 2021 г.

\begin{abstract}
Методом электронной микроскопии изучена топология поверхности тонких полимерных пленок, полученных на стекле из мицеллярных растворов образцов желатина в смеси изооктан-вода-(бис-2-этилгексил) сульфосукцинат натрия (АОТ) при вариации средней молекулярной массы $M$ полимера и постоянном молярном соотношении $\left[\mathrm{H}_{2} \mathrm{O}\right] /[\mathrm{AOT}]=40$. Показано, что из растворов с исходной концентрацией желатина, отвечающей порогу гелеобразования, формируются пленки с характерной структурой: в ячейках физической сетки зацеплений макромолекул - внутреннего перколяционного кластера частиц - находятся наноглобулы полимера. При этом с уменьшением $M$ падает средний размер глобул и растет степень их полидисперности. Такие же изменения наблюдаются для ячеек сетки, в которой ослабевают локальные корреляции типа плотность-плотность. Отношение средних размеров ячеек и наноглобул не зависит от $M$ вследствие универсальной фрактальной кластерной структуры пленок.
\end{abstract}

Ключевые слова: тонкие полимерные композиционные пленки, электронная микроскопия, наноглобулы, фрактальные кластеры, размерные эффекты.

DOI: 10.21883/FTT.2021.08.51174.082

\section{1. Введение}

В работе [1] на примере одного образца желатина (Gel) было показано, что из микроэмульсий этого полимера в смеси изооктан-вода-(бис-2-этилгексил) сульфосукцинат натрия (АОТ) возможно образование пленок со структурой типа „жидкость в твердом теле“. В качестве твердого каркаса пленок выступает физическая сетка зацеплений макромолекул - внутренний перколяционный кластер частиц [2]. В ячейках сетки находятся отображающие „жидкую“ фазу наноглобулы полимера [3]. Такая топологическая структура пленок формируется из мицеллярных растворов с исходной концентрацией желатина $c^{*}$, отвечающей порогу гелеобразования $[1,3]$. Если концентрация растворов превышает пороговое значение $c^{*}$, то происходит распад глобул и формируется однородная сетка мицеллярного геля [1].

В настоящей работе с использованием различных образцов Gel изучено влияние средней молекулярной массы $(M)$ полимера на топологию кластерной и глобулярной подструктур композиционных пленок. Пленки формировались из микроэмульсий Gel c исходной концентрацией полимера, равной величине $c^{*}$. Известно [4], что пороговая концентрация $c^{*}$ в расчете на водную фазу микроэмульсии зависит от параметра $M$, уменьшаясь с ростом $M$. В связи с этим особый интерес представляют два аспекта исследования: подтверждение универсального характера процесса самосборки фрактального кластера макромолекул при формировании пленок серии образцов Gel и установление закономерностей структурной трансформации при вариации значения $M$ полимера.
Отметим отдельно, что микроэмульсии линейных гибкоцепных полимеров могут быть использованы для создания твердотельных полимерных матриц, содержащих наночастицы различных веществ, в частности металлического золота, серебра, их солей, а также полупроводниковых кристаллов [5,6]. В технологии таких материалов золь-гель методом [7] актуальной задачей является регулирование пространственного распределения, размера, полидисперсности и стабильности наночастиц путем изменения молекулярно-массовых характеристик полимера и концентрационного режима получения композитов.

\section{2. Объекты и методы исследования}

В работе использовались следующие полимерные образцы: образец № 1 инертного $\mathrm{Gel}\left(M=10.3 \cdot 10^{4}\right.$, $c^{*}=3.3 \mathrm{~g} \cdot \mathrm{dl}^{-1} ;$,Rousselot ${ }^{4}$, Франция), представляющий собой узкую фракцию оссеина и не содержащий олигопептидов [1]; образец № 2 фотографического Gel $\left(M=8.9 \cdot 10^{4}, c^{*}=4.3 \mathrm{~g} \cdot \mathrm{dl}^{-1} ;\right.$ „Полимербото“, Россия), содержащий 10-30\% олигопептидов [4]; образец № 3 кислотного костного Gel $\left(M=5.8 \cdot 10^{4}\right.$, $\left.c^{*}=5.2 \mathrm{~g} \cdot \mathrm{dl}^{-1}\right)$, в котором $20-50 \%$ олигопептидов [4]. Полимерные пленки толщиной 4-6 $\mu \mathrm{m}$ формировались по методике [1] на стекле при $298 \mathrm{~K}$ из мицеллярных растворов образцов Gel в смеси изооктан-вода-АOT (молярное соотношение $\left[\mathrm{H}_{2} \mathrm{O}\right] /[\mathrm{AOT}]=40$ ). Исходная концентрация Gel в расчете на водную фазу соответствовала пороговому значению $c^{*}$ для каждого образца. 

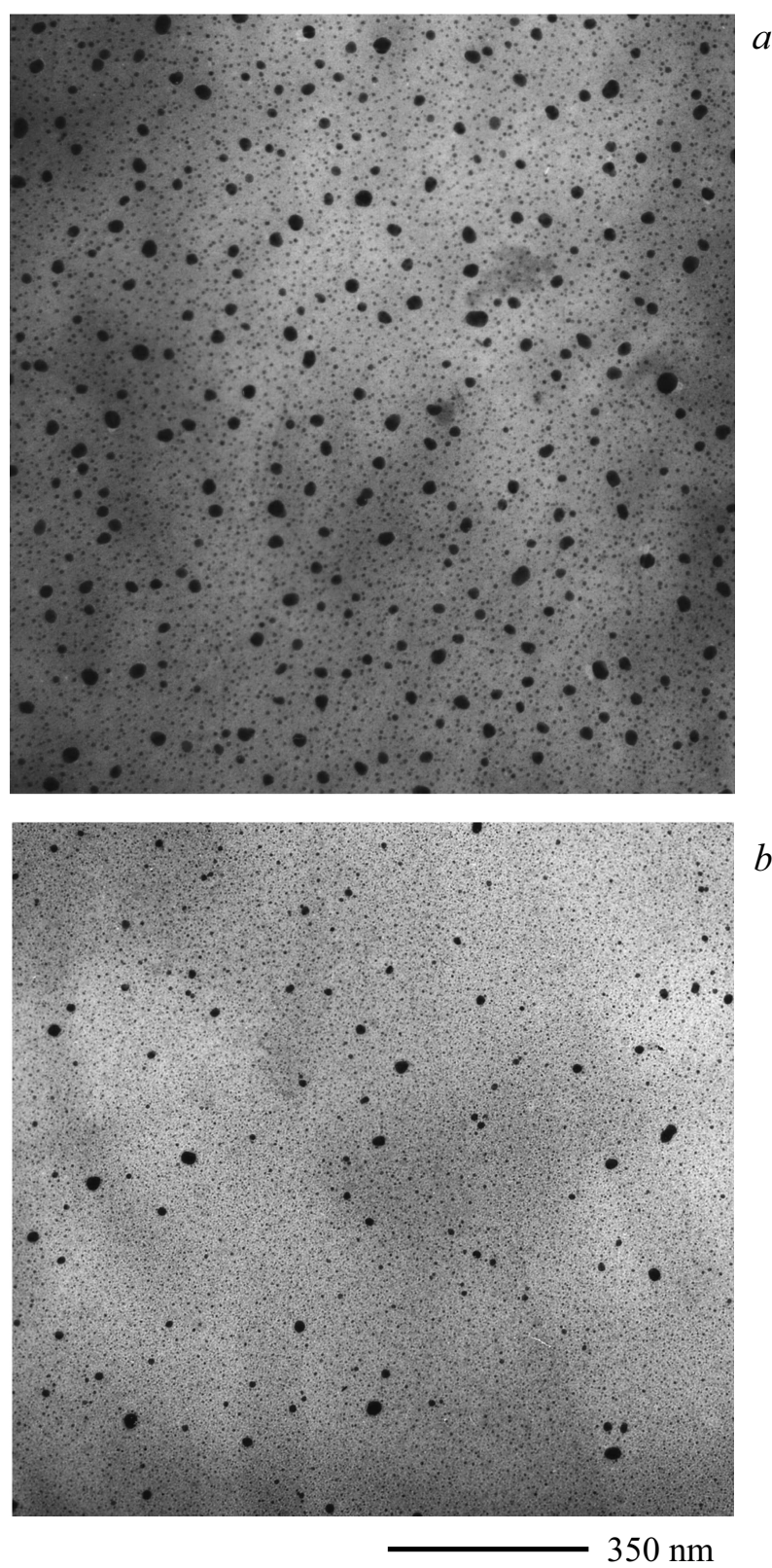

Рис. 1. Электронные микрофотографии декорированной поверхности пленок Gel: образец № $1(a)$, образец № $3(b)$.

Препарирование пленок для просвечивающей электронной микроскопии осуществлялось путем вакуумного термического декорирования „воздушной“ поверхности образцов хлоридом серебра и получения угольной реплики. В качестве центров зародышеобразования декорирующих наночастиц $\mathrm{AgCl}$ служили аминные и карбоксильные группы Gel [1].

На электронных микрофотографиях (рис. 1) можно выделить две размерные фракции наночастиц $\mathrm{AgCl}-$ мелких, диаметром $3-5 \mathrm{~nm}$, и крупных, диаметром 7-50 nm. Изображения крупных частиц имеют более высокую оптическую плотность. Согласно работе [1], мелкая фракция частиц отображает кластеры или агре- гаты макромолекул Gel, а крупным частицам отвечает глобулярное состояние Gel.

Компьютерная обработка микрофотографий включала построение радиальных функций $g(R)$ пространственного распределения декорирующих частиц для каждой из двух фракций в отдельности. Для получения функций $g(R)$ использовалось пошаговое сканирование плотности распределения частиц на микрофотографиях. Величина $\delta$ шага сканирования варьировалась относительно наиболее вероятного расстояния между частицами [8].

\section{3. Результаты и их обсуждение}

Средний диаметр $\langle d\rangle$ приблизительно сферических наноглобул в пленках образцов Gel изменяется симбатно со значением средней молекулярной массы $M$ полимера. При этом значение $\langle d\rangle$ составляет 20,16 и $12 \mathrm{~nm}$ для образцов № 1,2 и 3 соответственно (рис. 2). Отметим, что величина $\langle d\rangle$ больше среднего диаметра $d_{0}$ водных капель микроэмульсии, поскольку для соотношения $\left[\mathrm{H}_{2} \mathrm{O}\right] /[\mathrm{AOT}]=40$ величина $d_{0}$ составляет $10 \mathrm{~nm}$ [4]. Размер различных наночастиц, синтезируемых в растворах обратных мицелл, также обычно превышает размер водного пула [9].

С уменьшением значения $M$ растет полидисперсность наноглобул, а симметричная нормированная функция $f(d)$ их распределения по диаметру становится асимметричной и приобретает „хвост“ со стороны больших размеров (рис. 2). Уменьшение среднего размера наноглобул сопряжено с падением их концентрации на поверхности пленок: от $\sim 2 \cdot 10^{-4} \mathrm{~nm}^{-2}$ для образца № 1 до $\sim 6 \cdot 10^{-5} \mathrm{~nm}^{-2}$ для образца № 3. Последнее свидетельствует о динамической неустойчивости равновесия „малые наноглобулы $\leftrightarrow$ кластеры макромолекул“ при формировании пленок Gel.

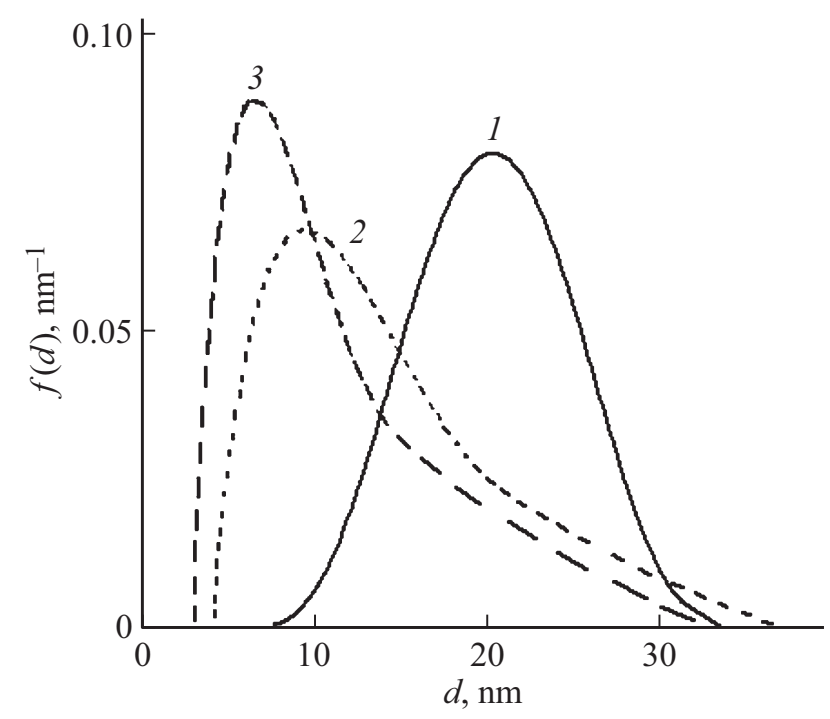

Рис. 2. Нормированные функции $f(d)$ распределения наноглобул по диаметру $d$. Образцы Gel: № 1 (кривая 1), № 2 (кривая 2), № 3 (кривая 3). 

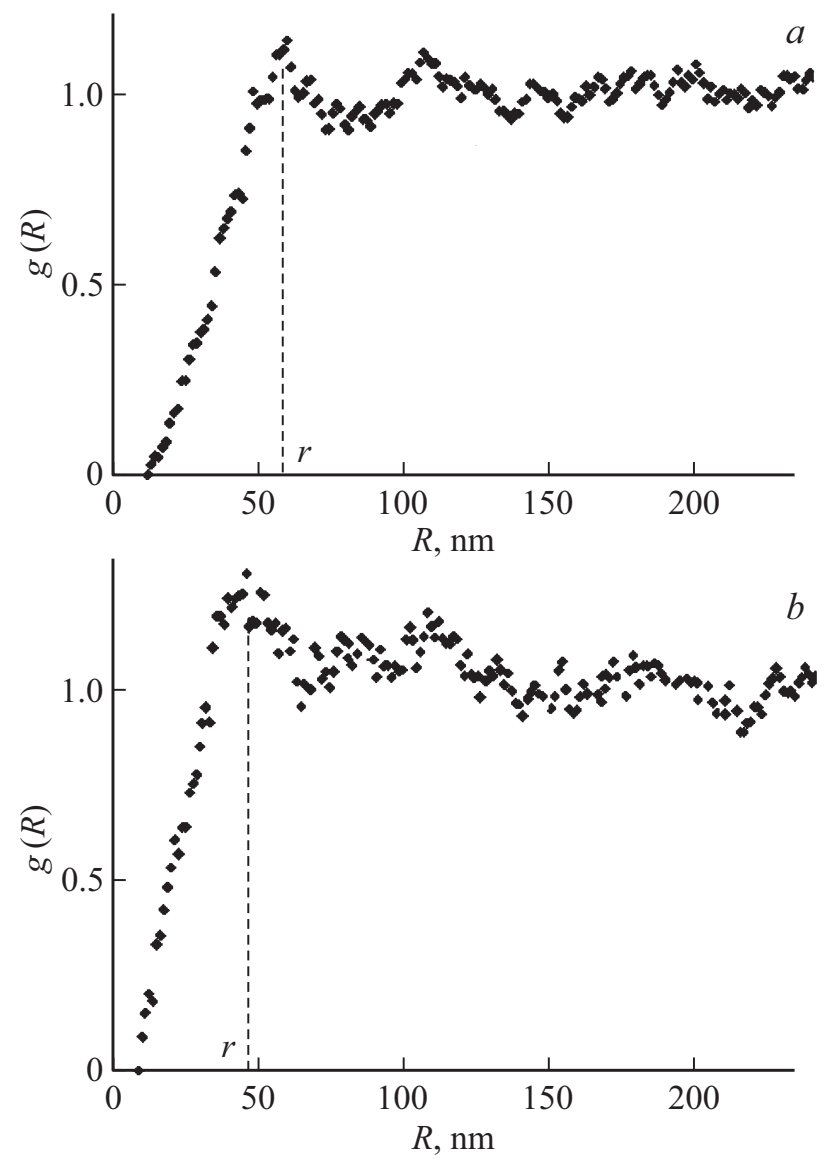

Рис. 3. Радиальные функции $g(R)$ распределения наноглобул на поверхности пленок Gel: образец № $1(a)$, образец № 3 (b). Шаг сканирования изображения поверхности $\delta=10 \mathrm{~nm}$.

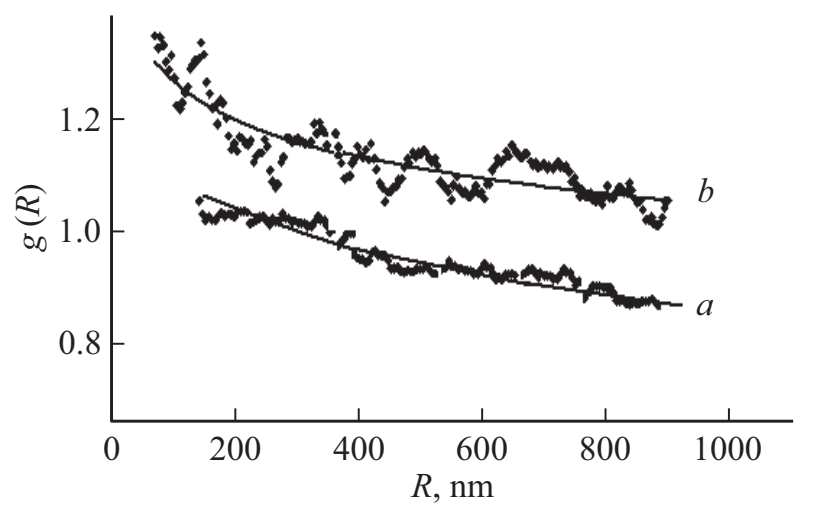

Рис. 4. „Крупнозернистые“ радиальные функции $g(R)$ распределения наноглобул на поверхности пленок Gel: образец № 1 (кривая $a$ ), образец № 3 (кривая $b$ ). Шаг сканирования изображения поверхности $\delta=60 \mathrm{~nm}$.

Распределение наноглобул на поверхности полимерных пленок можно представить в виде квазирешетки частиц, наиболее вероятное расстояние $r$ между которыми соответствует положению первого пика функции $g(R)$ (рис. 3). При этом среднее координационное число казирешетки [1] изменяется от 3.3 (образец № 1) до 1.2 (образец № 3), отношение $r /\langle d\rangle$ для всех образцов близко к 3, а пространственные корреляции между частицами распространяются на расстояние $\sim 2 r$ (рис. 3 ). Резкое падение среднего координационного числа при переходе от образца № 1 к образцу № 3 свидетельствует о разрушении квазирешетки наноглобул на отдельные фрагменты, что проявляется при сравнительном анализе соответствующих функций $g(R)$ (рис. 3). Второй пик функции $g(R)$ расширяется, расщепляясь при этом вследствие разупорядочения квазирешетки частиц [10].

Важной особенностью квазирешетки наноглобул является ее фрактальный характер. „Крупнозернистые“ корреляционные функции $g(R)$ для плотности распре-
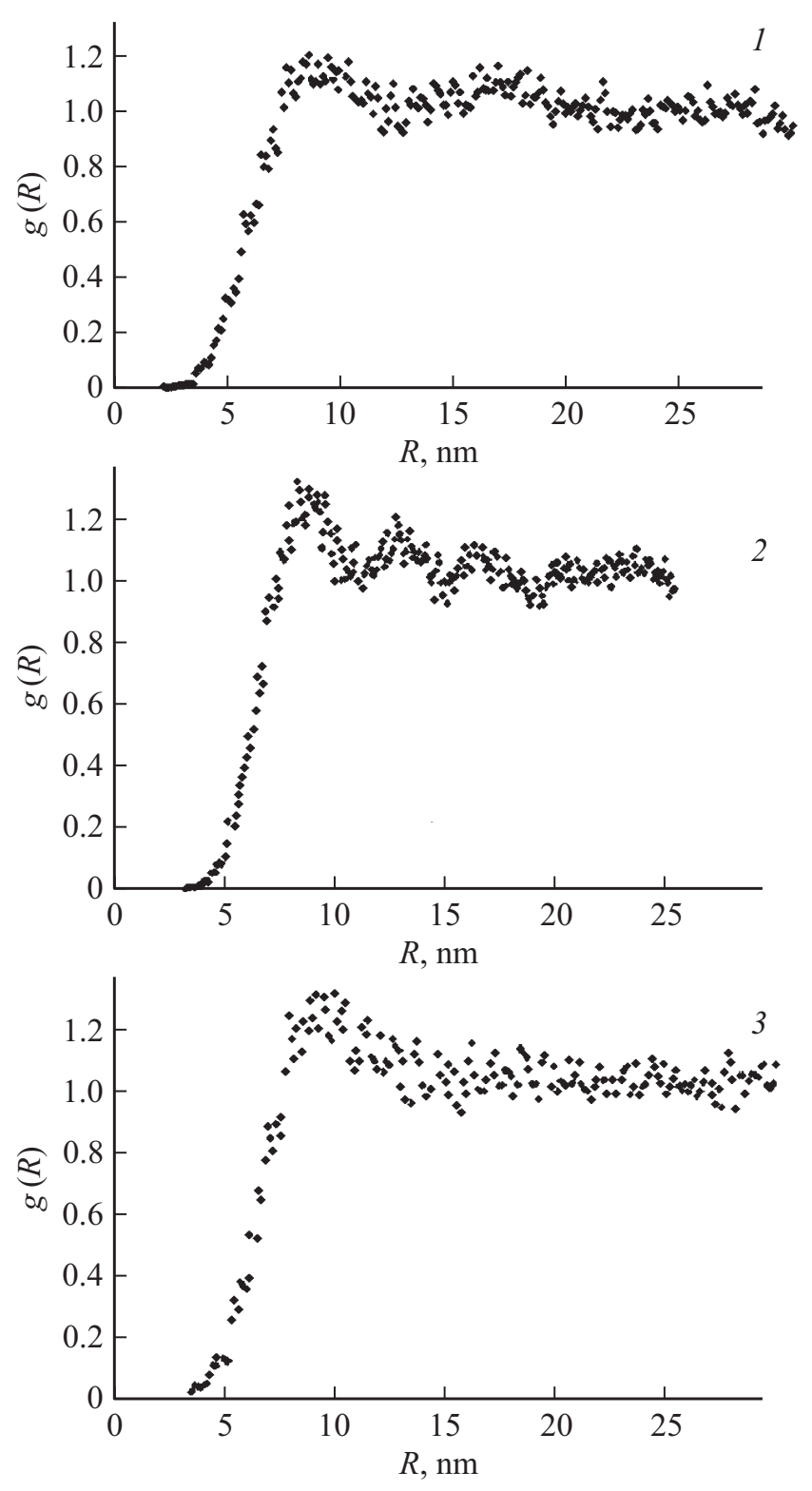

Рис. 5. Радиальные функции $g(R)$ распределения декорирующих наночастиц $\mathrm{AgCl}$, маркирующих физическую сетку макромолекул в пленках Gel. Шаг сканирования изображения поверхности $\delta=3 \mathrm{~nm}$. Образцы Gel: № 1 (кривая 1), № 2 (кривая 2), № 3 (кривая 3). 

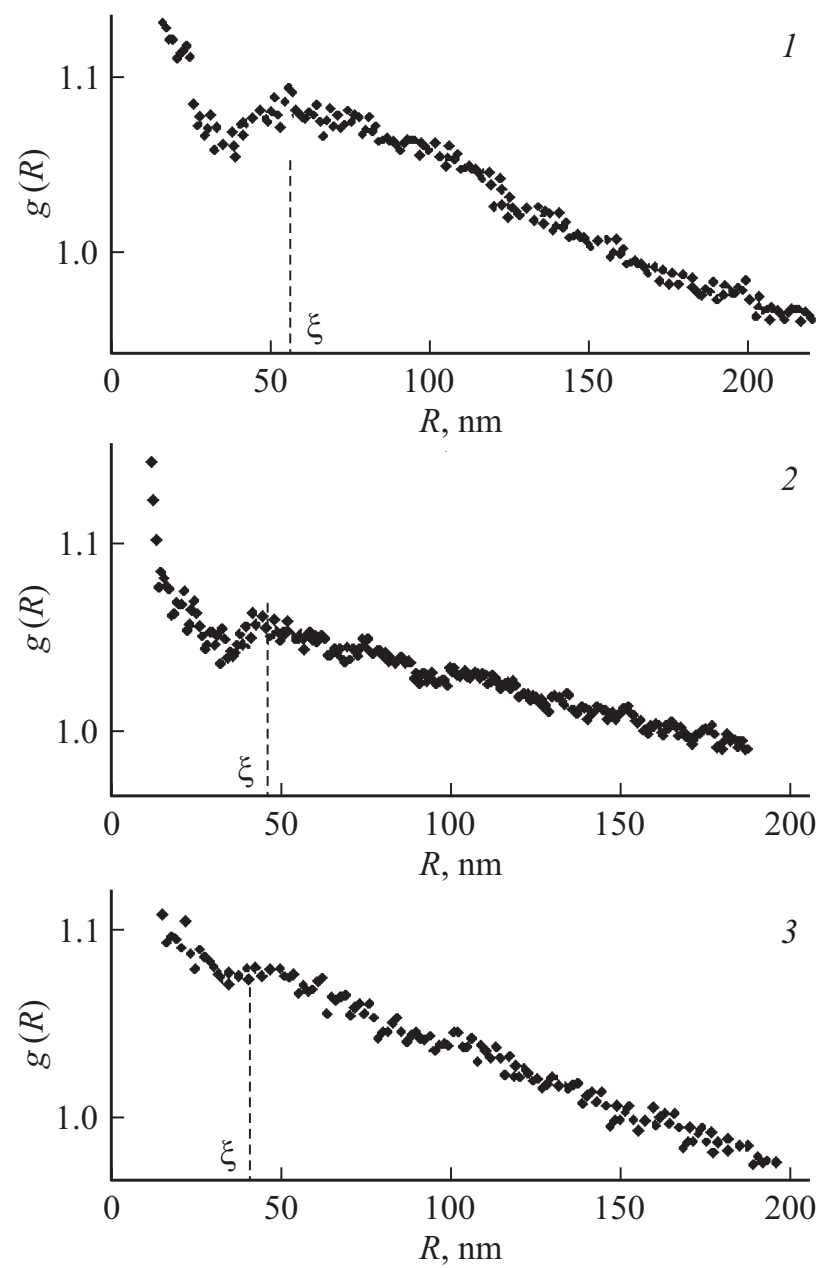

Рис. 6. „Крупнозернистые“ радиальные функции $g(R)$ типа плотность-плотность для физической сетки макромолекул. Шаг сканирования изображения поверхности $\delta=15 \mathrm{~nm}$. Образцы Gel: № 1 (кривая 1), № 2 (кривая 2), № 3 (кривая 3).

деления наноглобул на поверхности пленок спадают по одному степенному закону (рис. 4): $g(R) \propto R^{D-2}$, причем значение фрактальной размерности $D$ составляет $1.9 \pm 0.03$ в двумерном отображении поверхности. Разброс точек на графике функции $g(R)$ для образца № 3 увеличивается по сравнению с образцом № 1 (рис. 4), что объясняется ростом флуктуаций плотности распределения наноглобул за счет падения их концентрации на поверхности пленки.

Рост полидисперсности наноглобул, находящихся в ячейках сетки зацеплений макромолекул Gel, обусловлен увеличением степени разупорядоченности кластерной структуры полимера. Концентрация структурных дефектов в сетке изменяется симбатно с содержанием олигопетидов в образце Gel. Об этом свидетельствуют функции $g(R)$ декорирующих наночастиц $\mathrm{AgCl}$, маркирующих кластерную структуру $\mathrm{Gel}$ - физическую сетку макромолекул (рис. 5). С уменьшением параметра $M$ относительно образца № 1 (рис. 5, кривая 1) второй пик функций претерпевает характерные изменения [10]: сначала наблюдается расщепление пика (образец № 2; рис. 5 , кривая 2), а затем резко падает его интенсивность на фоне роста флуктуаций плотности распределения кластеров (образец № 3; рис. 5, кривая 3).

„Крупнозернистые“ корреляционные функции $g(R)$ типа плотность-плотность для кластеров макромолекул немонотонны (рис. 6) и типичны для систем с так называемым „промежуточным порядком“ [11]. Локальный максимум функций при $R=\xi$ соответствует корреляционной длине флуктуаций плотности или среднему размеру ячеек сетки. С уменьшением $M$ растет плотность узлов сетки, вместе с тем падают как корреляционная длина $\xi$, так и интенсивность пика функции $g(R)$. Последнее подчеркивает ослабевание локальных корреляций типа плотность-плотность. Отношение средних размеров ячеек и наноглобул не зависит от $M$. Отметим, что положение локального минимума функций $g(R)$ соответствует эффективному размеру агрегатов макромолекул в мицеллярном растворе на пороге гелеобразования [4].

На масштабе $R>\xi$ выполняется степенной закон падения плотности распределения кластеров, и корреляционные функции имеют вид: $g(R) \propto R^{-0.1}$ (рис. 6), свидетельствующий об универсальной фрактальной структуре физических сеток макромолекул в пленках серии образцов Gel. Сетки характеризуются фрактальной размерностью $D=1.90 \pm 0.02$, близкой к величине $D$ внутреннего перколяционного кластера [2]. В двух взаимодополняющих подструктурах изученных образцов физической сетке макромолекул и квазирешетке наноглобул Gel - совпадают как фрактальные размерности, так и размерные параметры: корреляционная длина $\xi$ и период $r$ соответственно (рис. 6 и 4).

\section{4. Заключение}

Для серии образцов $\mathrm{Gel}$, различающихся по молекулярно-массовым параметрам, установлена возможность формирования из мицеллярных растворов этого полимера пленок с универсальной структурой. Эта структура образована двумя взаимодополняющими фрактальными подструктурами: физической сеткой зацеплений макромолекул и квазирешеткой наноглобул Gel, находящихся в ячейках сетки. Необходимым условием образования данной композитной структуры является такой концентрационный режим образования пленок, при котором исходная концентрация мицеллярного раствора соответствует порогу гелеобразования.

Размерные параметры композитной структуры - корреляционная длина сетки и средний диаметр наноглобул - изменяются симбатно с молекулярной массой $\mathrm{Gel}$, а их соотношение не зависит от $M$. С увеличением содержания олигопептидов в образце Gel ослабевают пространственные корреляции типа плотностьплотность в кластерной структуре полимерных пленок, вследствие чего растет полидисперсность наноглобул.

Изученные образцы пленок Gel моделируют композитные материалы, свойства и режим получения которых можно регулировать изменением $M$ полимера. 


\section{Конфликт интересов}

Автор заявляет об отсутствии конфликта интересов.

\section{Список литературы}

[1] Д.В. Новиков, А.Н. Красовский. ФТТ 54, 2180 (2012).

[2] Е. Федер. Фракталы / Пер. с англ. Ю.А. Данилова и А.М. Шукурова. Мир, М. (1991). 254 с. [J. Feder. Fractals. Plenum Press, N.Y., London (1988). 260 p.].

[3] Г.М. Бартенев, С.Я. Френкель. Физика полимеров. Химия, Л. (1990). $432 \mathrm{c.}$

[4] А.Н. Красовский, А.И. Андреева. ЖПХ 69, 834 (1996).

[5] И.П. Суздалев. Нанотехнология: физико-химия нанокластеров, наноструктур и наноматериалов. КомКнига, М. (2006). $592 \mathrm{c}$

[6] П.В. Лебедев-Степанов. Введение в самоорганизацию и самосборку ансамблей наночастиц. НИЯУ МИФИ, М. (2015). 304 c.

[7] А.В. Андреева. Основы физикохимии и технологии композитов. ИПРЖР, М. (2001). 192 с.

[8] Д.В. Новиков. ФТТ 63, 146 (2021).

[9] C. Petite, P. Lixon, M.-P. Pileni. J. Phys. Chem. 97, 12974 (1993).

[10] R. Zallen. The Physics of Amorphous Solids. John Wiley \& Sons, N.Y. (2008). 319 p.

[11] Д.В. Новиков. ФТТ 60, 1829 (2018)

Редактор Т.Н. Василевская 